\title{
Using Forms Quizzes to Enhance Students' Motivation in Language Learning at a Japanese University
}

\section{Yoko Kita}

Kyoto Notre Dame University, Japan. E-mail:yokokita1o@gmail.com

\begin{tabular}{ll}
\hline ARTICLE INFO & ABSTRACT \\
\hline Keywords: & This study explores the effective utilization of the online program Forms via \\
forms, ICT, learner & $\begin{array}{l}\text { smartphones to enrich the classroom experience for both students and } \\
\text { motivation, quizzes, } \\
\text { smartphone challenges }\end{array}$ \\
instructor used Forms to create, distribute, collect, and analyze surveys and \\
quizzes. Students' attitudes toward English and their motivation to learn the \\
language using these tools were examined. Via smartphones, they were given \\
review quizzes that had game-like elements and that gave feedback in real \\
time. Surveys investigating the degree of confidence in learning, the review \\
quizzes, and smartphone usage were also distributed to their smartphones. \\
The results indicate improvement in attitude towards English in general and \\
enhanced confidence.
\end{tabular}

DOI:

http://dx.doi.org/10.21093

/ijeltal.v5i2.661

\section{How to cite:}

Kita, Yoko. (2021). Using Forms Quizzes to Enhance Students' Motivation in Language Learning at a Japanese University. Indonesian Journal of English Language Teaching and Applied Linguistics, 5(2), 219.235

\section{Introduction}

The emergence of Information and Communication Technology (ICT) has been an incentive for English educators to familiarize themselves with its utilization in the field of language education. In addition, various reforms have been implemented since globalization has demanded drastic changes to Japanese English education. From this perspective, the collaboration of English education and ICT is indispensable. It is expected that appropriate utilization of ICT in English education will enable enhancement of the process of language learning. The Japanese Ministry of Education, Culture, Sports, Science, and Technology 
(MEXT) has introduced various cases of the effective usage of ICT in English lessons (MEXT 2017; MEXT, 2018).

University educators also advocate for the utilization of ICT into lessons (Kaya, 2020; Kita, 2019; Kita, 2020; Mabushi, 2020; Milliner \& Barr, 2017; Nakata, 2020; Nishiwaki, 2019; Takiguchi, 2018). Many universities provide Office 365 which includes Office Forms, Teams, OneDrive, and Outlook as well as fundamental software: Word, Excel, and PowerPoint. However, various kinds of applications (apps) that support ICT education are available online free of charge. University educators and students can easily download apps on mobile devices and PCs.

The gradual pervasion of ICT has also changed the data collection style from paper-based to online. Surveys created by Google Forms and Microsoft Forms are used to collect information and data from users. Recently, conference attendance records have been collected through Google Forms or Microsoft Forms. Google Forms and Microsoft Forms, formerly called Office Forms, are probably the most commonly used versatile tool in creating questionnaires for surveys. Nakamura \& Nakamura (2019) report the practical usage of Google Forms in collecting lesson questionnaires. Microsoft Forms (Forms) is available to Office 365 Education users such as university staff and students, and users with a Microsoft account. Microsoft (2020) introduced the benefit of using Forms with the following:

With Microsoft Forms, you can create surveys, quizzes, and polls, invite others to respond to it using almost any web browser or mobile device, see real-time results as they submitted, use built-in analytics to evaluate responses, and export results to Excel for additional analysis or grading.

University teachers can sign in with their Microsoft 365 university account and create a new form or quiz. When sharing new forms or new quizzes with their students, teachers send a QR-code for their forms. Using mobile phones and scanning the QR code sent by teachers, students can easily access the forms or quizzes to respond and submit their answers. The results of the quizzes pop up on their smartphones immediately so students can get test results promptly. Accumulating small successful experiences might enable students to gradually enhance learning motivation. Teachers can also see response summary information and individual results for quizzes or surveys (Microsoft, 2020).

In regard to mobile devices promoting ICT associate education, smartphones and tablets are pervasive in Japanese university students' lives. It is reported that $99 \%$ of university students own smartphones (Mobile Society Research Institute, 2019). On the other hand, approximately $70 \%$ of university students own personal computers (PC) in 2020 (TesTee, 2020). Oshikiri (2020) mentions that $23 \%$ of university students at his university own tablets. $\mathrm{He}$ also reports that during the Covid-19 pandemic, $20 \%$ of students attended university online lessons via smartphone. Many university instructors attempted online classes via PC during the Covid-19 pandemic in early 2020; however, the initial issue was that some students could not access online lessons due to lack of PCs, which might have interfered in promoting online lessons.

Ishihara (2019) explicitly suggests the importance of English language learning enhanced with smartphones. He also emphasizes that education should foster autonomous learners who are motivated in language learning inside and outside of classes. It implies that ICT, 
particularly smartphones, has the potential to be a useful tool in enhancing students' motivation leading to the promotion of language proficiency. In a case study involving smart phone usage, Yamauchi (2017) draws attention to students' engagement with Kahoot, an online game-based classroom response system.

Some case studies on effective smartphone usage in language learning have been reported (Yamaguchi, 2017; Ishihara, 2019; Oshikiri, 2020). On the other hand, there are fewer studies on Forms usage in English lessons. Although studies on Google Forms and Office Forms as data collection systems have been published (Amazaki, 2018; Unser-Schutz, 2019; Yuji, 2020), Forms usage in language learning should be explored more. Therefore, this study attempts to implement the effective usage of Office Forms via smartphone in the classroom, especially using review quizzes to enhance student's motivation in language learning.

This study sets out to answer the following research question:

1. How can we utilize Microsoft Forms (Forms) in English lessons?

2. What are the perceptions of Liberal Arts English students about using quizzes via smartphone? 1) Does it help students to build confidence for Eiken Grade Pre-2 \& 2 vocabulary and grammar skills? 2) Does it help to enhance the student's motivation in language learning? 3) Does it help students to like English better than before?

\section{Literature review}

The following section briefly reviews studies on three main points regarding: 1) The relationship between motivation and language learning; 2 ) The usage of smartphones and ICT in language learning; 3) The usage of Forms in language learning

\subsection{Language learning and motivation}

In language learning, motivation is often considered an important factor in determining success (Dörnyei, 1994; Tsumura, 2010; Tsumura, 2011; Yoshida, 2009; Yamato \& Mikami 2012). Extrinsic and intrinsic motivations are widely acknowledged. However, Yoshida (2009) explicates a motivation, which is the condition of lacking motivation in language learning. She mentions that motivation, extrinsic motivation, and intrinsic motivation are all connected but rather in different stages. Upon reaching the stage "Identified regulation," learners will be motivated to study a language for their personal interest and value.

Yamauchi (2017) discusses how low English proficiency learners tend to have a negative attitude towards English learning due to a lack of successful experiences in learning English and failed tests while in school. One easily conceivable possibility for students to be demotivated is if they are continuously experiencing getting low grades, or being embarrassed during English classes. In Japan, English learning formerly began at the age of twelve at secondary school; however, English lessons nowadays start at the age of nine. The longer students are exposed to unsuccessful learning experiences, the further they are demotivated toward English learning. University educators reported the following:

One of the resulting factors was a motivation, which positively correlated with an aversion to making an effort, resistance to grammar and vocabulary learning, and anxiety about using English (Agawa et. al., 2011., 13).

They also state that "demotivated English learners tend to make less effort, which likely lowers their competence" (Agawa et. al., p14). Here is another important factor: 
the relationship between self-efficacy and language learners' grades (Templin, 1999). Selfefficacy is important due to its influence on an individual's performance. A person with high self-efficacy towards a task pays more attention, makes a greater effort, and is more persistent (Early \& Lituchi, 1991; Lee \& Bobko, 1994).

There is no doubt that the influence of self-efficacy is as valuable as enhancing motivation toward learning a language. It raises an important point. How should educators bring both of these elements into the classroom to improve the learner's experience?

\subsection{The usage of ICT and smartphones in language learning}

In 2017, Academic eXchange for Information Environment and Strategy (AXIES) conducted a survey in 792 universities and found that $98.1 \%$ of universities systematically promoted ICT usage. On the other hand, for teachers individually, only $12.7 \%$ promoted ICT usage. Most of the ICT usage conducted at university lectures consisted of the following: PowerPoint, online materials and video, and Learning Management Systems. The utilization of mobile devices accounted for only $\mathbf{1 7 . 7 \%}$. Kaya (2020) noted the potential of mobile devices in university English classrooms.

Hinkelman, et. al. (2008) discusses mobile phone technology integration into open-source learning management systems for university general education classes. To illustrate students' interest in using a mobile phone as learning devices, they mention "Younger students seem to have an advantage in this field due to their extensive use of mobile phones" (Hinkelman et. al., p 175). Houser \& Thornton (2004) state university students show interest in mobile usage learning applications. They also discovered the speed at which university students input sentences into mobile phones.

In considering the usage of smartphones in English lessons, Ishihara (2019) advocates strongly for its benefits. He posits, "Smartphones are ideal tools for language learning due to their convenience, accessibility, combining voice and visual media information with portability" (Ishihara, 2019, p 48). However, he points out that efficient teaching methods and material development are still insufficient; teachers, therefore, need to work on them.

\subsection{The usage of Forms in language learning}

Regarding Forms, the two most frequently used ones are Google Forms provided by Google LCC and Microsoft forms by Microsoft. Amazaki (2018) approaches the student's attendance system via smartphone and management via Google Forms. Yuji (2020) attempts the utilization of Microsoft Forms to collect prompt comments via smartphone during the lessons. Neither study has an accordance with English education; however, the efficiency of Forms in collecting data is exemplified. In Forms surveys, the Semantic Differential method seems to be used frequently.

Unser-Schutz (2019) provided students with video lessons embedded in Google Forms. His intent was for the students of a required speaking class to watch the videos and to conduct reviews at home for homework, thus allowing more time in class for productive and active exercises. Although realizing the benefits of the system, he pointed out the downside, which is it requires a big workload.

Kurasawa (2018) illustrates the diverse usage of Google Forms (Forms). When explicating practical usages in education, he summarizes the following three points. 1) Teachers create 
surveys and polls and invite students and teachers to respond to them using web browsers and not paper-based responses. 2) Teachers create surveys for feedback questionnaires regarding current lessons and invite students to respond to them, which enables teachers to utilize them as lesson evaluations. In addition, responses to surveys are automatically collected into charts with real-time response information. 3) Teachers utilize Forms as basic tests and quizzes when setting distribution points and choice of the correct answers. He points out the downside of using Forms for tests. He mentions that teachers may face issues of not being able to confirm the students' attendance in the classroom during tests. Using mobile phones and scanning the QR code sent by teachers, there is a possibility that students can easily access the quizzes to respond and submit their answers without physically being in the classroom. Therefore, it is difficult for teachers to utilize Forms for regular testing. However, he maintains that "It is meaningful to use Forms as quizzes to review lessons."

Regarding the benefits of the usage of Forms in closed-response questions, Milliner \& Barr (2017, p 77) stated the following:

The answers are displayed in a clearly labelled pie chart...Learners seem to engage with these activities because the feedback is quick, and the data is based on real content generated by the learners themselves.

Another promising study displayed the utilization of quizzes written using Google Forms when taking vocabulary assessment (Rylander, LeBlanc, Lees, Schipper, \& Milne, 2018). They deem Google Forms a practical tool: "Google Forms allowed for ease in the creation and editing of questions... enabled the teacher-researchers to share information and divide workloads easily" (Rylander et. al., 2018, p 89).

In addition, Yamauchi (2018) conducted game-based classroom response systems. She concludes "Kahoot! could play an important role in helping low proficiency EFL learners by engaging them in learning." When conducting review quizzes, the researcher should take into consideration fun game-like elements. Current smartphone studies involving language learning have a focus on pedagogical aspects such as teaching vocabulary, grammar, and listening in addition to the use of social media apps (Agea \& Ozdemir, 2013; Ishihara, 2019; Mabushi, 2020; Yamauchi, 2018; Sung \& Poole, 2017).

\section{Research Methodology}

\subsection{Research Design}

Using classroom-based action research, this study intends to investigate ICT usage in Liberal Arts English at a Japanese university. This study was designed to determine to what extent the usage of ICT enhances students' motivation to learn English and monitor attitudes towards English in general. It involves utilization of Microsoft Forms (Forms) to monitor the perceptions of students about using quizzes via smartphone.

\subsection{Site and Participants}

In this study, participants represented first-year university students at a teacher's college in Japan enrolled in Liberal Arts, English Reading I \& II Courses for the spring and fall semesters in the 2019 academic year. English Reading, I is conducted in the spring semester: English Reading II is conducted in the fall semester. Both are in-class, face-to-face lessons. The participants are students at the Naruto University of Education. The age of the participants 
ranged from 18 to 19. Approximately 120 undergraduate students in the first year were divided into three classes: Class A, B and C. Each class had approximately 40 students; however, the class sizes may have had slight variations depending on how many extra students they had who had failed the previous academic year. One instructor was assigned to each class; however, in the fall semester, these classes switched instructors.

The total participants in this study $(n=74)$ were comprised of two groups of students. In the 2019 English Reading I Course, the researcher was in charge of class C, which consisted of 37 students (17 males and 20 females): the majors of the students were physical education, home-economics, social studies, technology, and special needs education. The percentage of students with Eiken Grade 2 or Grade Pre-2 English proficiency in the English Reading I course is $43.2 \%$ according to the pre-course survey. In the 2019 English Reading II course, the researcher was in charge of Class $A$, which consisted of 37 students ( 16 males and 21 females): the majors of the students were math, music, school education, and English. The percentage of students with Eiken Test Grade 2 or Grade Pre-2 English proficiency in the English Reading II Course is $37.8 \%$ : Grade Pre-1 level students account for $2.7 \%$, according to the pre-course survey.

Students at the University of Education take the Teachers' Exams in the fourth year, although some students might qualify for an exemption from the English conversation test if they have previously passed the Eiken Test Grade 2 . This is dependent on the prefecture and the level of the teachers' exam.

\subsection{Procedure}

Reading I \& II are part of a compulsory course worth two credits each semester in one academic year. The course is composed of 16 90-minute lessons. The course grades are based on $20 \%$ e-learning, $70 \%$ for the two examinations, and $10 \%$ in-class assignments. Students are assigned to take the STEP EIKEN TEST (Eiken) at the end of each semester and are instructed to report the results to the university's Student Affairs Office.

Reading I Course Objectives are as follows: the goal is to develop the necessary knowledge and English proficiency to pass the Eiken Grade Pre2. The Reading II Course Objective: the goal is to develop the necessary knowledge and English proficiency to pass the Eiken Grade 2. The Eiken Grade Pre-2 and Grade 2 both consist of three sections: reading, writing, and listening at the first stage. The Reading section includes questions, sentence completion, fill in the gap dialogues, fill in the gap passages, and Q\&A based on passages. In the English Reading I \& II Courses, the same textbook is used in Class A, B and C. Instructors can use some supplementary teaching materials as well. The textbook provides four main practices: building up vocabulary and grammar knowledge, long and short reading passages, and writing and listening practice. During lessons, instructors focus on developing reading and listening skills for the Eiken.

Due to the students' different backgrounds in English learning, the researcher assessed the student's English Proficiency before beginning the study. In addition, the researcher surveyed the students' learning attitude and motivation: 1) students' attitude or motivation toward learning English 2) whether she/he likes English, 3) students' reasons for their like or dislike of English 4) confidence regarding Eiken Grade Pre-2 vocabulary and grammar skills and other sections. There has been much research about the relationship between motivation 
and language learning. Research shows that there is a strong correlation between motivation toward English learning and achievement. Students' attitude toward English learning is as important as being familiar with their academic background. Considering those elements when designing a practical lesson is fundamental, which aids students in promoting English proficiency and enhancing their confidence to pass the EIKEN TEST at the end of the course. The researcher utilized Office Forms (Forms) for surveys.

The pre-course and post-course surveys for the English Reading I \& II Courses included the following questions: 1) Have you ever taken the Eiken Test? If so, which grade did you take? Which grade do you currently have? 2) Do you like or dislike English? Why do you feel that way? 3) How confident are you for Eiken Grade Pre-2 vocabulary and grammar skills? 4) How confident are you for Eiken Grade Pre-2 long and short passage reading skills? 5) How confident are you for Eiken Grade Pre-2 listening skills? 6) What is your goal for learning English?

As a result of the pre-course survey, the researcher determined that students expect to build up vocabulary and grammar knowledge to cope with the Eiken. Since many of the students' attitudes toward English learning were lukewarm, concrete countermeasures to enhance the students' motivation were definitely required. All students possess smartphones, and during orientation the instructor observed that the students were easily using their smartphones and typing amazingly fast when scanning and sending surveys or looking up vocabulary. Hence, the researcher attempted to conduct vocabulary and grammar quizzes via smartphone when reviewing each lesson. As seen in the literature review (Yamauchi, 2018), game-based classroom response systems could play an important role in helping low proficiency learners by engaging them in learning. Working on the review quizzes generated by Forms could be a small step; however, it could be worth trying. The vocabulary and grammar quizzes are generated based on what students learn in-class. The review quizzes were composed of 10 questions with five multiple-choice questions from lesson 1 to 6 . From lesson 7 12, the quizzes were composed of 10 questions with fill-in the blanks, which are slightly more challenging than multiple-choice quizzes. The researcher utilized Forms to create review quizzes and a QR code, which allowed students easy access. Students scanned the code with their smartphones using a QR code reader and worked on review quizzes. The students could get feedback in real-time, viewing the grading of the quizzes on their smartphones. In postclass surveys, the researcher added the following questions: 1) How satisfied are you with the review quizzes? 2) How satisfied are you with the use of smartphones for review quizzes inclass? 3) type in Japanese with specific comments on the usage of quizzes via smartphone for reviews.

\subsection{Data Collection and Analysis}

The researcher conducted the pre-course and post-course assessments using Forms Questionnaires for the survey were created using Forms and its QR code was generated. The instructor projected the code onto a screen, which enabled students to scan the code with their smartphones using a QR code reader. Since Forms is provided by the university and only students are allowed to access the system, all students' responses are automatically archived. The students are not required to type in their personal information; when logging in to the university account, their student ID, first and last name, login and logout time, and course name are automatically archived once students submit their answers to the questionnaire. 
In class, Forms was used to create quizzes and generate QR codes with the researcher conducting 15 review quizzes via smartphone per semester. Based on the information of precourse surveys and achievement goals of the course, the researcher attempted quizzes for quick vocabulary and grammar review. As seen in the literature review, it is possible for Forms to be utilized for basic tests and quizzes when setting distribution points and choices of the correct answers.

All responses to surveys and quizzes were automatically collected into charts with real-time response information. Forms allows students to access real-time grading feedback on a scale of 100 points. In addition, students can view the summary of responses, the data based on real-time content generated by them on the screen monitor when the instructor shares the responses in class. The summary of answers is displayed in a clearly labeled pie chart.

Since both students' responses to pre- and post-course surveys and quizzes were automatically archived, the researcher accessed the archived data and downloaded it as Excel sheets to analyze. The downloaded data on the Excel sheets was converted to Tables. The data on the pre- and post-surveys was displayed and analyzed.

\section{Results and Discussion}

\subsection{The Utilization of Forms in English Lessons}

Previous researchers (Rylander et al., 2018; Amazaki, 2018; Yuji, 2020) have deemed Google Forms practical and easy to use. Similarly, this researcher was able to use Forms to create quizzes and generate $Q R$ codes while conducting 15 review quizzes that students were able to access via smartphone. Besides survey tools, the researcher utilized Forms when creating quizzes for quick vocabulary and grammar review.

\subsection{The perceptions of Liberal Arts English students about using the quizzes via smartphone}

The following is the research question: 1 ) Did the quizzes help students to build confidence for Eiken Grade Pre-2 \& 2 vocabulary and grammar skills?

Graph 1 and Graph 2 present a summary of the results regarding the question "How confident do you feel about Eiken Grade Pre-2 vocabulary and grammar skills?" in Reading Course I. This survey was conducted to measure the improvement in their confidence from 15 periods of lessons for their preparation for the Eiken Test's vocabulary and grammar sections. The pre-course and post-course results are in order and as follows: "I am very confident" $0.0 \%$ to $2.7 \%$; "I have some confidence" $20.6 \%$ to $51.4 \%$; "I am not super confident" $32.4 \%$ to $13.5 \%$ ; "I am not confident" $29.5 \%$ to $24.3 \%$; "I am not confident at all" $17.6 \%$ to $8.1 \%$. 


\section{I am very confident.}

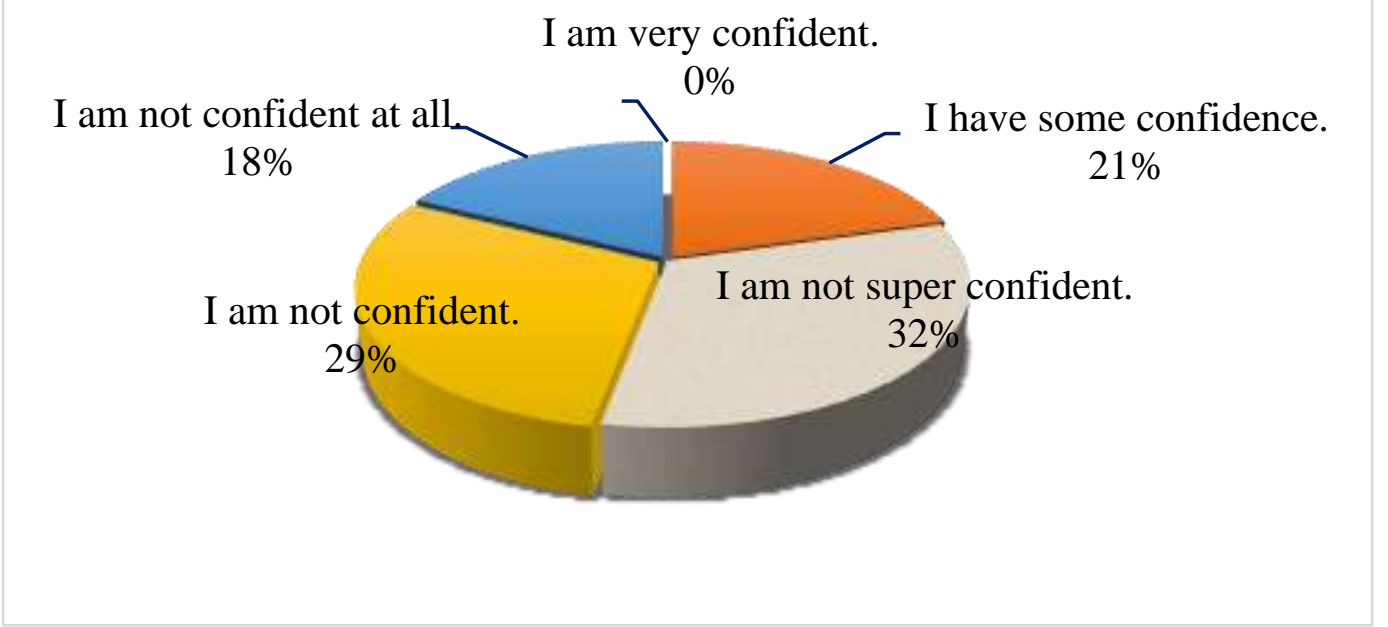

Graph 1 : The level of confidence for Eiken Grade Pre-2 vocabulary and grammar skills Pre-course Survey

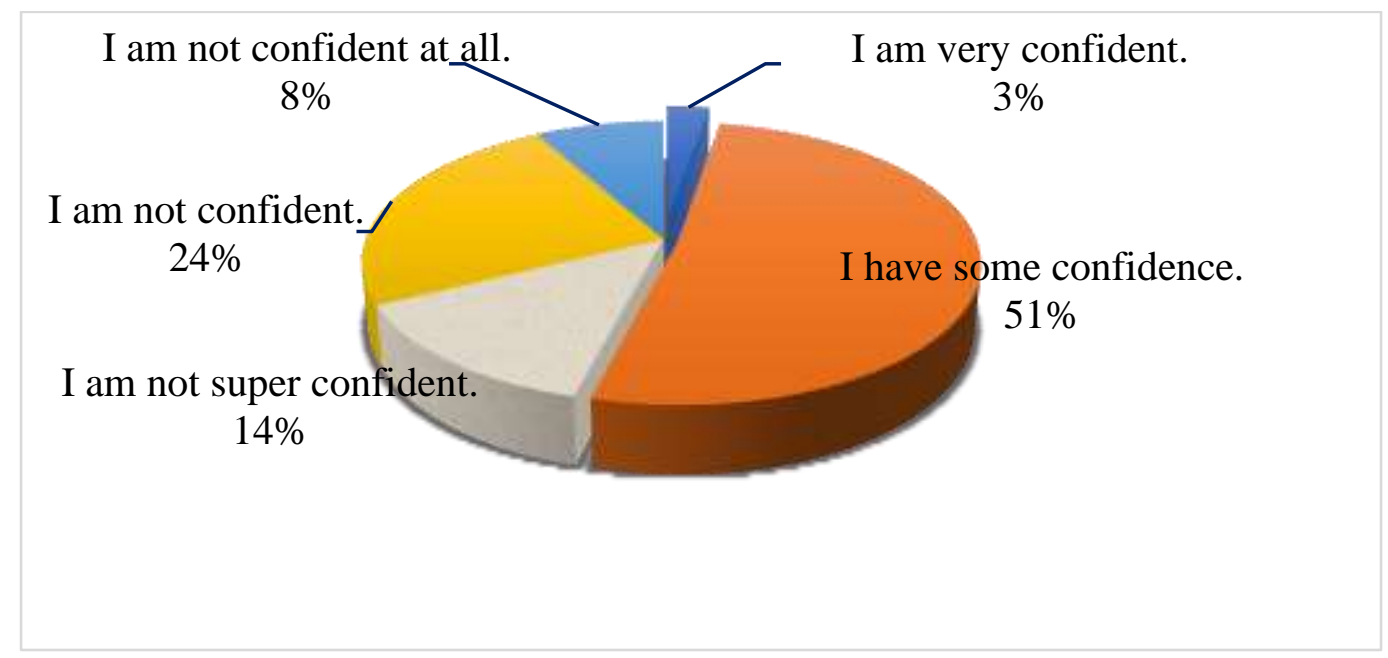

Graph 2 : The level of confidence for Eiken Grade Post-2 vocabulary and grammar skills Pre-course Survey

There is a conceivable reason why the percentage of "I have some confidence" went up from $20.6 \%$ to $51.4 \%$. According to the survey conducted at the beginning of the spring semester, approximately 40 percent of students in this course answered "I rather disliked" or "I did not like English at all" (see Table 1), so they might not be motivated to study English while in school. As Yamauchi (2017) and Agawa et.al (2011) mentions, students who have failed tests in school and who have a lack of successful experiences in English classes tend to dislike the subject. Those students might have been exposed to unsuccessful learning experiences and become demotivated toward English learning; therefore, they simply did not study harder. While attending the 15 periods of lessons, students were accumulating small but steady successful learning experiences, and they might have gained a certain level of confidence.

Graph 3 and Graph 4 present a summary of results regarding the question "How confident do you feel about Eiken Grade 2 vocabulary and grammar skills?" in Reading Course II. The pre- 
course and post-course results are in order and as follows: "I am very confident" $2.8 \%$ to $12.1 \%$; "I have some confidence" $5.6 \%$ to $12.1 \%$; "I am not confident" $38.1 \%$ to $21.2 \%$; "I am not confident at all" $13.9 \%$ to $6.1 \%$.

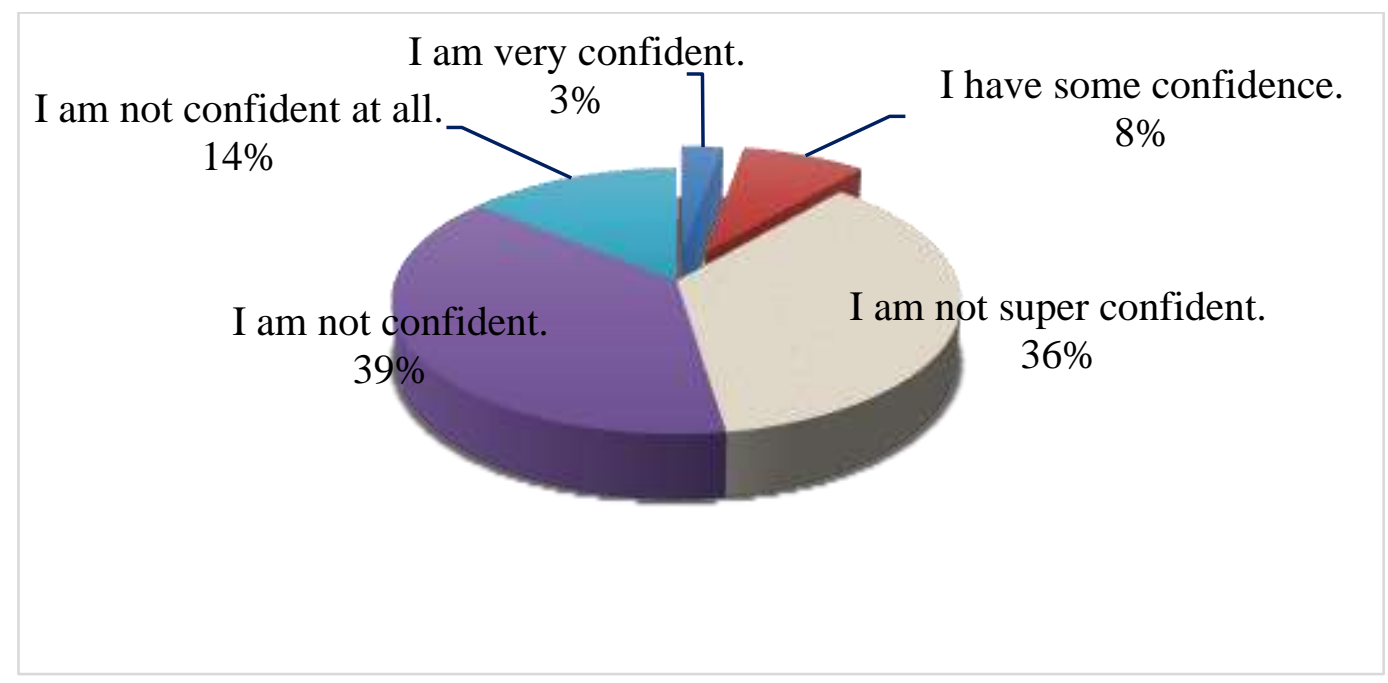

Graph 3 : The level of confidence for Eiken Grade 2 vocabulary and grammar skills Pre-course Survey

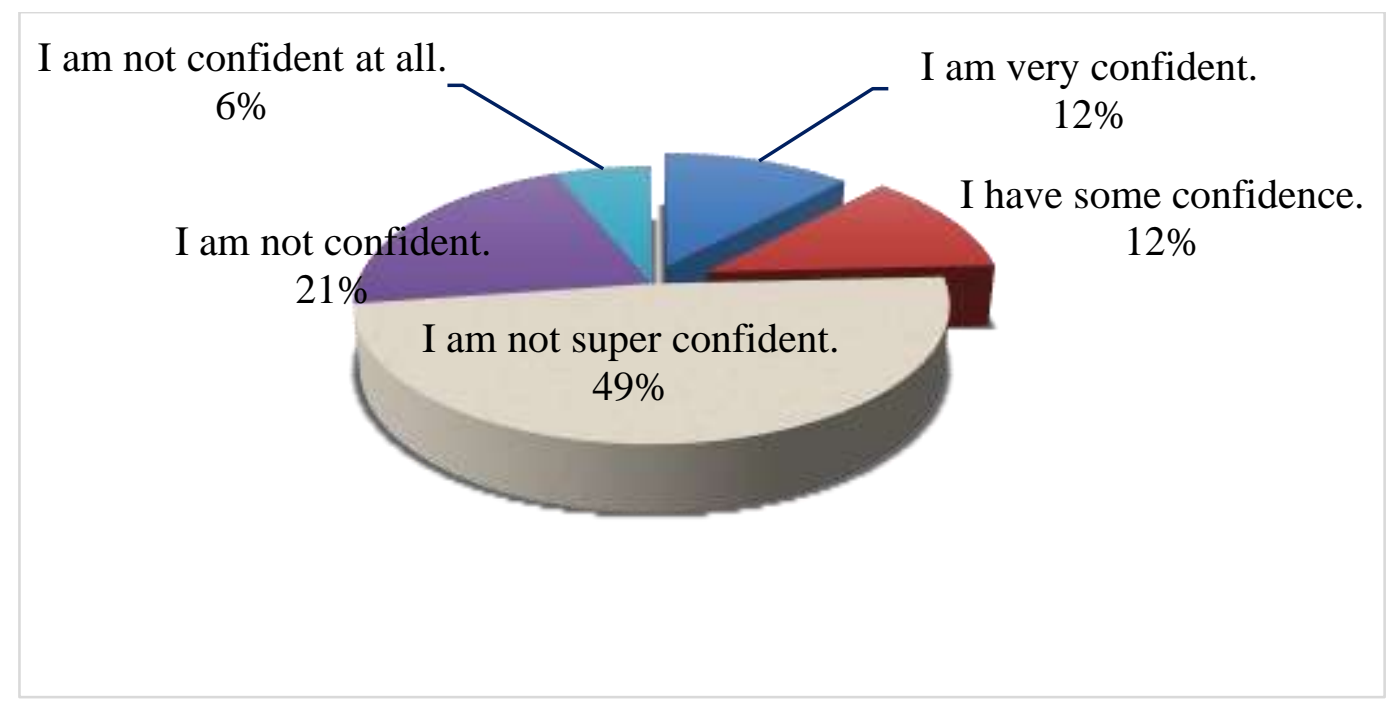

Graph 4 : The level of confidence for Eiken Grade 2 vocabulary and grammar skills Pre-course Survey

The results show students gained confidence for Eiken Grade Pre-2 and 2 vocabulary and grammar skills through 15 periods of lessons. Although the percentage of "I am not confident at all" dropped from $13.9 \%$ to $6.1 \%$, they indicate the researcher needs to take further measures to increase confidence by building up students' vocabulary and grammar skills.

The following is the next research question: 2 ) Did the quizzes help to enhance the student's motivation in language learning?

Graph 5 presents a summary of results from the Reading I and II Courses regarding the question "How satisfied are you with the review quizzes?" This question was asked only in 
post-course surveys to assess whether the vocabulary and grammar quizzes for review were effective. Personal satisfaction could build up self-efficacy and enhance motivation in language learning (Early \& Lituchi, 1991; Lee \& Bobko, 1994). The result indicates that the students were satisfied overall with the vocabulary and grammar quizzes. The students' opinions collected through Forms surveys seem to support the effectiveness of review via vocabulary and grammar quizzes. These findings concur with the research of Kurasawa (2018) and Milliner \& Barr (2017). The extracted comments are as follows:

"It was easy and convenient to review the vocabulary and idioms I just learned.

"It is convenient to work on review quizzes because you just need 5 mins at the end of lessons."

As previous researchers (Early \& Lituchi, 1991; Lee \& Bobko, 1994) mentioned, the influence of self-efficacy is as valuable as enhancing motivation toward learning a language. Students' comments also indicated that review quizzes could affect learning motivation:

"It is a good way to review my progress. I thought that I had memorized all the vocabulary and idioms I had learned in the class. However, the results of the review quizzes turned in with my smartphone made me realize that I had not memorized them as well as I had thought."

"When I got a complete score, it filled me with confidence. I felt the sense of a tiny accomplishment, although it was a very small step."

"Seeing the results of my quizzes got me motivated to work harder for the Eiken Test. I really do want to pass the Eiken Test."

These findings concur with the research of Dörnyei (1994); Tsumura (2010); Tsumura (2011); Yoshida (2009); Yamato \& Mikami (2012). The vocabulary and grammar review quizzes were simple and had game-element activities, as suggested by Yamauchi (2018), which seemed to provide students with small successful learning experiences during the 15 periods of lessons.

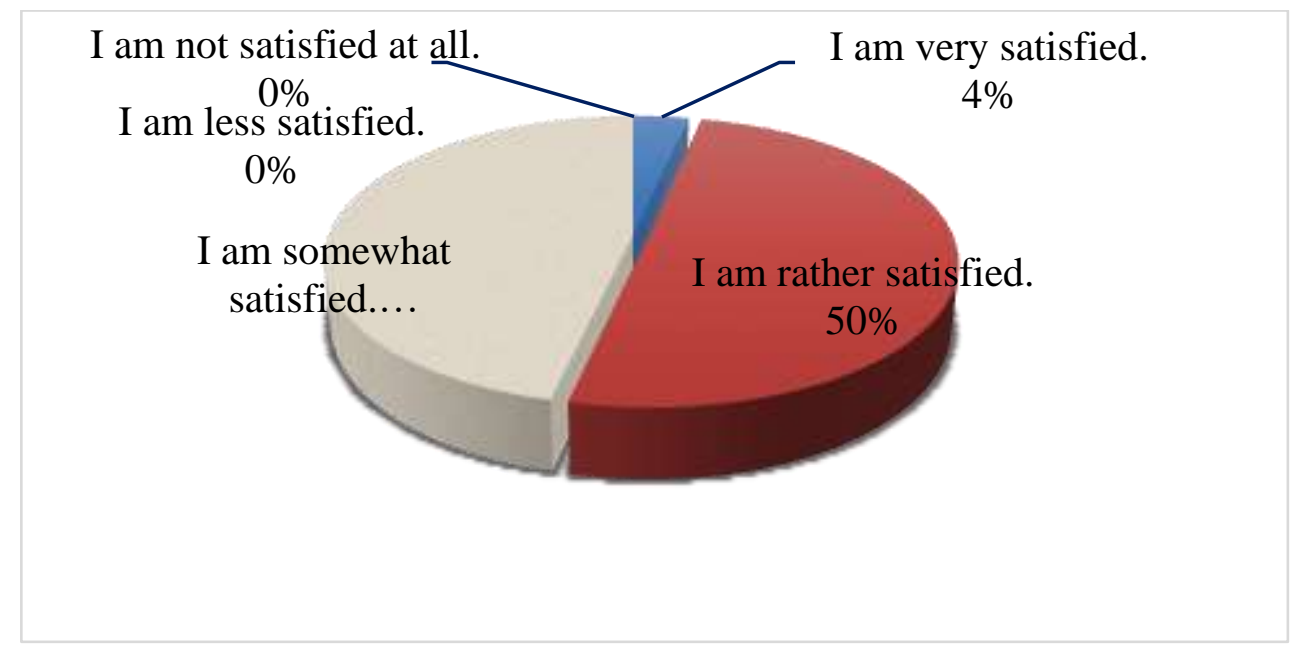

Graph 5 : The level of the students' satisfaction with the review quizzes in Reading $1 \& 2$

The following is the last research question: 3 ) did the quizzes help students to like English better than before? 
The following four tables show the students' attitude toward English. This survey intended to measure emotional changes, if any, in the students after the 15 periods of lessons. Table 1 and Table 2 present a summary of results regarding the question "Do you like English?" in Reading Course I.

Table 1: Students' attitude toward English Pre-course Survey

\begin{tabular}{ll}
\hline The degree of preference & Response Rate \\
\hline I like English very much. & $2.7 \%$ \\
I rather like English. & $40.5 \%$ \\
It is ok. & $16.2 \%$ \\
I rather dislike English. & $29.7 \%$ \\
I don't like English at all. & $10.8 \%$ \\
\hline
\end{tabular}

Table 2: Students' attitude toward English Post-course Survey

\begin{tabular}{ll}
\hline The degree of preference & Response Rate \\
\hline I like English very much. & $5.6 \%$ \\
I rather like English. & $41.7 \%$ \\
It is ok. & $33.3 \%$ \\
I rather dislike English. & $16.7 \%$ \\
I don't like English at all. & $2.8 \%$ \\
\hline
\end{tabular}

Table 3 and Table 4 present a summary of results regarding the question "Do you like English?" in Reading Course II.

Table 3 : Students' attitude toward English Pre-course Survey

\begin{tabular}{ll}
\hline The degree of preference & Response Rate \\
\hline I like English very much. & $13.8 \%$ \\
I rather like English. & $22.2 \%$ \\
It is ok. & $19.4 \%$ \\
I rather dislike English. & $36.1 \%$ \\
I don't like English at all. & $8.3 \%$ \\
\hline
\end{tabular}

Table 4 Students' attitude toward English Post-course Survey

\begin{tabular}{ll}
\hline The degree of preference & Response Rate \\
\hline I like English very much. & $17.6 \%$ \\
I rather like English. & $41.2 \%$ \\
It is ok. & $29.4 \%$ \\
I rather dislike English. & $5.9 \%$ \\
I don't like English at all. & $5.9 \%$ \\
\hline
\end{tabular}

The results show the students' attitude becoming more positive toward English through 15 periods of lessons. In Reading Course II, students have a positive attitude toward English from 
the beginning; however, the percentage of students that responded "I rather dislike English" dropped all the way to $5.9 \%$.

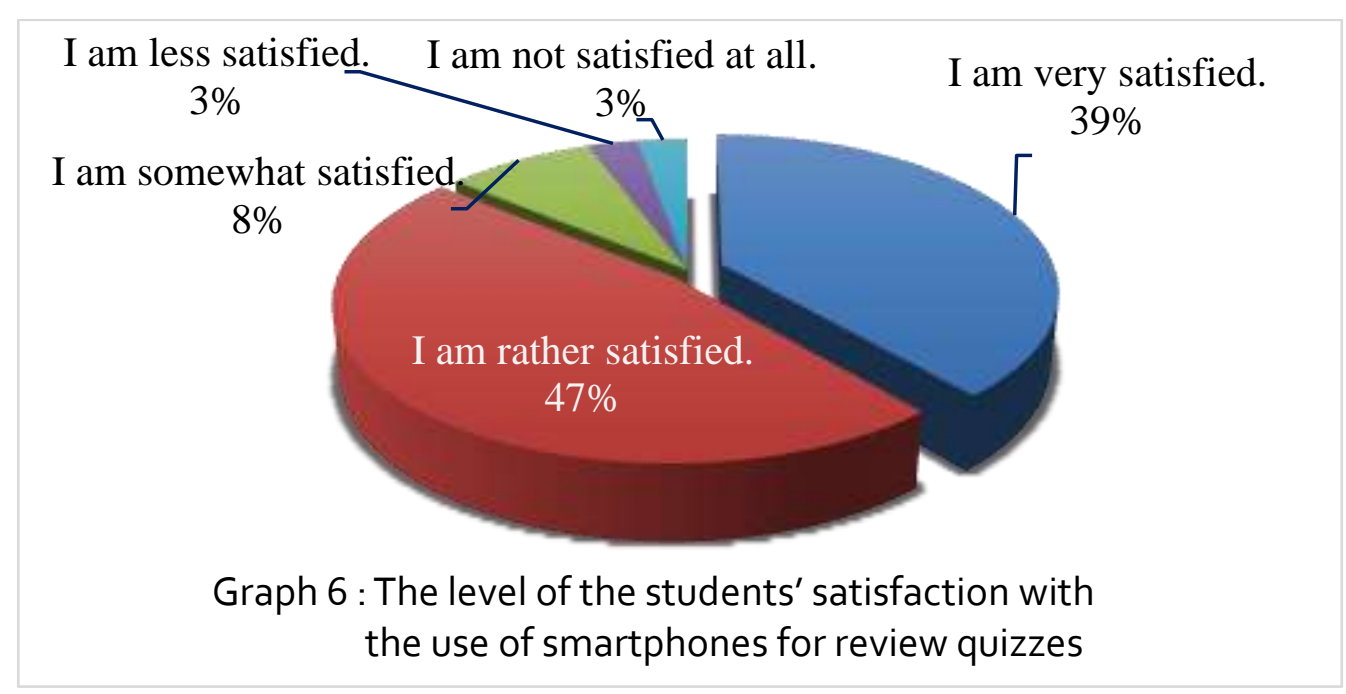

Graph 6 presents a summary of results from the Reading I and II Courses regarding the question "How satisfied are you with the use of smartphones for review quizzes?" This question was asked only in post-course surveys to assess if the usage of smartphones for review quizzes of vocabulary and grammar was effective. The results indicate that the students were satisfied overall with the smartphone usage for the vocabulary and grammar quizzes. The students' opinions to support this data is presented at the end of this section.

Regarding classroom style, smartphone usage for review quizzes, and motivation toward English lessons, the researcher collected students' comments. These findings are in line with previous research regarding the effective usage of smartphones in language learning (Yamaguchi, 2017; Ishihara, 2019; Mabushi, 2020). Many students appeared satisfied with the usage of smartphones for review quizzes:

"It is easy to access with my smartphone in order to take review quizzes.

It is a convenient way to review because I get my score right after I answer the questions."

"Once I answered all questions, I could get my score immediately, which is very convenient."

Templin (1999) mentions an important factor -- the relationship between self-efficacy and language learners' grades. The students' comments indicate the effect.

"I can get the results of my test (quizzes) immediately so I know what vocabulary I should work on for the tests. When I got full marks,100 points, it filled me with confidence."

By contrast, the researcher also received some comments from students not satisfied with the usage of smartphones for review quizzes.

"I sometimes forgot to bring my smartphone to class. I had to use my friend's smartphone. I did not like it." 
"I was not so happy when typing words in English, I prefer multiple choice. Typing words in English was pretty difficult for me."

As Agawa et.al (2011) mentioned, the researcher has to be careful about the students' aversion to making an effort. This is a manifestation of an insufficient preliminary survey about students' fundamental ICT literacy. In considering any ICT usage in the classroom even that of smartphones, the researcher should have grasped the students' ICT literacy.

In this study, there are notable limitations. The researcher would have liked to have presented the data of how many students passed the Eiken as a result of the lessons; however, due to personal information protection, we could not access this data. Another issue is that the results of the surveys were still insufficient. Despite the fact that the comparisons between tables (see Table 1, 2,3,4) seemed to illustrate students' attitudes toward English improved, the researcher saw limitations of the analysis. There was no way to directly correlate the results with having enhanced the student's motivation in learning English. Asked about the drawbacks of this study, the researcher would mention the difficulty of assessing students' degree of motivation and satisfaction accurately as a percentage that convinces all researchers. It could be a consideration for future research in the collaboration of ICT usage and language education.

\section{Conclusion}

In this study, the researcher attempted to utilize smartphones and Forms in creating vocabulary and grammar review quizzes as effective usage of ICT in English lessons. The researcher used Forms to create 15 review quizzes, generate QR codes and collect data on the result of the quizzes. In reply to the first research question, we can utilize Forms efficiently to implement quizzes as well as collect survey data. The researcher's suggestions could be applied to other language activities besides vocabulary and grammar quizzes. In answering the second research question, students showed affirmative responses to being engaged in review quizzes via smartphone. According to the survey results, it is indicated that the students' satisfaction with the use of smartphones for review quizzes is relatively high. The researcher also received positive opinions regarding the utilization of review quizzes via smartphone. The conceivable reason to support this is the following. The grading feedback is in real-time and simple. Additionally, it has game-element activities which could be dealt with by students at different levels of proficiency. Regarding the enhancement of student's motivation in learning a language, the surveys as the result of 15 periods of lessons showed an improvement in their confidence. Students left positive comments mentioning that an accumulation of small but steady successful learning experiences enhanced their motivation toward learning. Indeed, they were motivated to study harder to pass the Eiken test. Nonetheless, further study is needed for appropriate assessments of students' degree of motivation enhancement.

In language learning, motivation is considered an important factor to be a successful learner. The researcher concludes that it is important to make the best use of ICT to enhance students' motivation in language learning. The emerging growth of Information and Communication Technology has been offering multiple options for language learning. We have been seeing more and more free downloadable smartphone apps which students can utilize in their language learning. In this study, the effective usage of Forms, which the university provided, 
assisted by smartphones in language learning was examined. In the future, the researcher will address the efficient usage of social media apps on smartphones in language learning.

\section{References}

Academic eXchange for Information Environment and Strategy. (2019). Research on the Utilization of ICT in Higher Education Institutions: Report of the investigation. https://axies.jp/_media/2020/03/2019_axies_ict_survey_v2.1.pdf.

Agawa, T., Abe, E., Ishizuka, M., Ueda, M., Okuda, S., Carreira-Matsuzaki,, J., Shimizu, S. (2011). Preliminary study of demotivating factors in Japanese university English learning. The Language Teacher the Language Teacher 35.1, 35(1), 11. https://doi.org/10.37546/jalttlt35.1-2

Agca, R. K., \& Özdemir, S. (2013). Foreign language vocabulary learning with mobile technologies. Procedia - Social and Behavioral Sciences, 83, 781-785. https://doi.org/10.1016/j.sbspro.2013.06.147

Amazaki, M. (2018). A students' attendance system using smartphones: Management OneDrive and Google Forms. Journal of Information Education, Aichi University, 43, 2539.

Dörnyei, Z. (1994). Motivation and motivating in the foreign language classroom. The Modern Language Journal, 78(3), 273-284. https://doi.org/10.1111/j.1540-4781.1994.tbo2042.x

Earley, P., \& Lituchy, T. (1991). Delineating goal and efficacy effects: A test of three models. Journal of Applied Psychology, 76(1), 81-98. https://doi.org/10.1037/0021-9010.76.1.81

Hinkelman, D., Okuda, O., Johnson, A., Ishikawa, S., \& Grose, T. (2008). Mobile phone technology integration into open source LMS for university general Education classes in Japan. Journal of the Society of Humanities, Sapporo Gakuin University, 83, 173-202.

Houser, C., \& Thornton, P. (2004). Japanese college students' typing speed on mobile devices. Proceedings of the 2nd IEEE International Workshop on Wireless and Mobile Technologies in Education, 19-31.

Ishihara, T. (2019). English language learning enhanced with smartphone. Mejiro University Departmental Bulletin Paper, 25, 47-52. http://id.nii.ac.jp/1514/00001565.

Kaya, T. (2020). ICT-enhanced English learning methods for Japanese university students. Intercultural Communication Review, 18, 91-104. http://doi.org/10.14992/00019162.

Kita, Y. (2019). A study of class observation in elementary and junior high language education using AR: Active learning and effective feedback. Journal of Information Education, Naruto University of Education, 16,17-20. http://doi.org/10.24727/00028465.

Kita, Y. (2020). A study on effective usage of ICT in reflection: An approach to the practice of English lessons. Journal of Information Education, Naruto University of Education, 17,5457. http://doi.org/10.24727/00028606.

Kurasawa, T. (2018). Usage of the "Google Apps" for educational purposes(2)Google Forms. Journal of Information Education, Shiraume Gakuen University, Junior College, 21, 33-40.

Lee, C., \& Bobko, P. (1994). Self-efficacy beliefs: Comparison of five measures. Journal of Applied Psychology, 79(3), 364-369. https://doi.org/10.1037/0021-9010.79.3.364

Mabushi, K. (2020). Development of an English learning app and its evaluation. Bulletin of School of Professional Development in Education (SPDE), Nara University of Education, 12, 1-10. 
MEXT. (2017). The Revision of the Courses of Study for Lower Secondary School. Retrieved from https://www.mext.go.jp/component/a_menu/education/micro_detail/_icsFiles/afieldfil e/2019/03/18/1387018_010.pdf.

MEXT. (2018). ICT utilization instruction improvement training implementation model for "improvement of ICT utilization instruction" of elementary, lower secondary school and secondary school teachers with new learning guidelines. https://www.mext.go.jp/component/a_menu/education/micro_detail/_icsFiles/afieldfil e/2018/09/07/1408990_1.pdf.

Microsoft. (2020). Microsoft Forms. Retrieved from https://support.microsoft.com/jajp/forms.

Microsoft. (2020). Microsoft Forms - Easily create surveys, quizzes, and polls. Retrieved from https://forms.office.com/.

Milliner, B., \& Barr, B. (2017). Computer-assisted language tests for the English classroom: Blackboard ${ }^{\circledR}$ tests and Google Forms. The Center for ELF Journal, 3, 67-79. https://doi.org/info:doi/10.15045/ELF_0030107

Mobile Society Research Institute. (2019). mobile white paper 2019. Retrieved from https://www.moba-ken.jp/whitepaper/wp1g.html.

Nakamura, M., \& Nakamura, M. (2019). Aggregation of lesson questionnaires. Bulletin of Hiroshima Kokusai Gakuin University, 52, 37-41.

Nakata, M. (2020). Active learning using ICT — Examples of ICT use- Bulletin of Hiroshima Jogakuin University, 67, 1-11.

Nishiwaki, K. (2019). Utilization of ICT at the beginning and end of one unit of English class. Aichi Bunkyo University Educational Research, 10, 9-18.

Oshikiri, T. (2020). Survey results of SNS usage rate and PC smartphone penetration rate of college students. https://www.cuttysark.co.jp.

Rylander, J., LeBlanc, C., Lees, D., Schipperr, S., \& Milne, D. (2018). Validating classroom assessments measuring learner knowledge of academic vocabulary. http://hdl.handle.net/2433/231228.

Sung, K., \& Poole, F. (2017). Investigating the use of a smartphone social networking application on language learning. The JALT CALL Journal, 13(2), 97-115. https://doi.org/10.29140/jaltcall.v13n2.214

Takiguchi, H. (2018). The learning effect of ICT in Japanese university English education. Surugadai University Studies, 56, 119-132.

Templin, S. A. (1999). The relationship between self-efficacy and language learners' grades. JALT Journal, 21(1), 112-124.

TesTee. (2020). Survey on personal computer and internet literacy. Retrieved from https://lab.testee.co/pc-result_2020.

Tsumura, S. (2010). A study on demotivating factors: in relation to students' likes and dislikes of learning English? The Osaka Syogyo Daigaku Ronshu, 5(5), 27-42.

Tsumura, S. (2011). Relationship between self-esteem and demotivating factors in English learning. JALT2010 Conference Proceedings. https://jalt-publications.org/files/pdfarticle/jalt201oproc-79.pdf.

UNSER-SCHUTZ, G. (2019). Preparing to switch your classroom: Creating and using online lessons. Journal of Institute of Psychology, Rissho University, 17, 35-41. 
Yamato, R., \& Mikami, Y. (2012). Survey and investigation of Japanese EFL learners' motivation: From the perspective of $\mathrm{L} 2$ motivational self-system. Bulletin of Kyoto Sangyo University Teaching Profession, 7, 1-21.

Yamauchi, M. (2017). Boosting student engagement with Kahoot!, 43, 18-23. https://doi.org/10.14949/konpyutariyoukyouiku.43.18.

Yoshida, K. (2009). A study on motivation in language learning. Bulletin of Environment and Information Department, Musashi University of Technology, 10, 118-113.

Yuji, H. (2020). A study of participating classes using smartphones use of Microsoft Forms and Papa Comments. Journal of Information Education, Naruto University of Education, 17, 1-8. 